\title{
INSTITUIÇÕES E SUJEITOS: SABERES E PODERES NO PROCESSO DE REORGANIZAÇÃO/OCUPAÇÃO DAS ESCOLAS Públicas do eStado de São PaUlo
}

\author{
INSTITUTIONS AND SUBJECTS: KNOWLEDGE AND STRENGTH IN THE \\ PROCESS OF REORGANIZATION/OCCUPATION OF PUBLIC SCHOOLS IN \\ THE STATE OF SÃO PAULO
}

Anailton de Souza Gama Doutor em Letras, Universidade Presbiteriana Mackenzie (UPM) São Paulo, SP - Brasil anailton@uems.br

Roseli Trevisan Marques de Souza Doutora em Educação, Faculdade de Educação da Universidade de São Paulo - FE-USP São Paulo, SP - Brasil rtms1962@gmail.com

\begin{abstract}
Resumo: Neste artigo será apresentada uma análise discursiva da entrevista coletada em 2016 sobre o tema “A reorganização e as ocupações das escolas públicas do Estado em 2015”. Cabe informar que no presente texto procuramos resgatar a memória de uma mãe de um estudante que participou juntamente com o filho do movimento estudantil denominado ocupações. Destaca-se que tal registro representa parte da memória da participante. O trabalho analítico que objetiva apresentar alguns sentidos dessa memória está sustentado na abordagem metodológica presente no título Gestos de Leitura: da história do discurso, organizado por Eni Puccinelli Orlandi (2010), o qual, por sua vez, está embasado nos princípios de Análise do Discurso de linha francesa que tem como um dos expoentes Pêcheux (2006).
\end{abstract}

Palavras-chave: Reorganização. Ocupações. Memória. Educação Básica.

\begin{abstract}
This article will present a discursive analysis of the interview collected in 2016, on the theme "The reorganization and occupations of public schools in the State of São Paulo in 2015". I would inform you that in this text try to rescue the memory of a mother of a student who participated along with the son of the student movement called occupations. It is noteworthy that this record represents part of the participant's memory. The analytical work that aims to present some meanings of this memory, is supported by the methodological approach present in the title Gestures of Reading: the history of discourse, organized by Eni Puccinelli Orlandi (2010), which, in turn, is based on the principles of Analysis of the French line speech, which has as one of the exponents Pêcheux (2006).
\end{abstract}

Keywords: Reorganization. Ocupations. Memory. Basic Education.

\section{Para citar - ABNT NBR 6023:2018}

GAMA, Anailton de Souza; SOUZA, Roseli Trevisan Marques de. Instituições e sujeitos: saberes e poderes no processo de reorganização/ocupação das escolas públicas do estado de São Paulo. Cadernos de Pós-graduação, São Paulo, v. 19, n. 2, p. 173-193, jul./dez. 2020. Disponível em: https://doi.org/10.5585/cpg.v19n2.18261. 


\section{Introdução}

Em 2015, alguns jovens estudantes ocuparam as escolas estaduais para impedir o fechamento de 94 estabelecimentos de ensino da Rede de Ensino de São Paulo. Tratava-se de uma política pública que, além de fechar escolas, reorganizaria um pouco mais de uma centena de outros espaços escolares. Dentre os argumentos utilizados pelos governantes estava a redução da natalidade, que inevitavelmente geraria ambientes ociosos. Diante disto, seria importante transferir os estudantes dos estabelecimentos esvaziados e disponibilizá-los para outros fins. Tal compreensão da realidade não era tão clara aos estudantes que decidiram ocupar as escolas. Como o diálogo entre as partes não foi viabilizado, tais alunos se mantiveram firmes no movimento até que o decreto fosse revogado.

Esse momento histórico foi relatado em artigos e na pesquisa de Doutorado intitulada $A$ Reorganização e as ocupacões das escolas da rede pública estadual de ensino paulista em 2015: um registro de memória ${ }^{1}$. Uma das etapas desse processo investigativo constitui em foram as entrevistas com os participantes do movimento estudantil. No atual artigo, nos propomos a analisar (AD) um relato feito por uma mãe de um estudante que ocupava a E.E.V.F.P². A impressão da senhora entrevistada acerca da ação do Estado de reorganizar a escola de seu filho colocava em xeque o discurso dos representantes da SEE-SP. Nossa análise visa, portanto, apresentar o ponto de vista da Sra. Arlete sobre a reorganização da escola de seu filho e as implicações dessa política intempestiva para o cotidiano deles.

Para tanto, a condução analítica partirá da metodologia da Análise do Discurso (AD) cuja enunciação, segundo Orlandi (2010, p.14), nos remete a um "campo novo de questões" que busca os sentidos discursivos. Pêcheux (2006), um dos expoentes da área, conseguiu unir três campos de conhecimento para esse fim: a linguagem, as ciências sociais e a história, esta última objetivando o resgate do acontecimento e da memória daqueles sujeitos com pouca voz no cenário social. Os três campos citados, no entanto, são relevantes ao presente estudo porque a memória se embasa no fenômeno linguístico para expressar a realidade vivida pelos envolvidos no conflito social. Nesse sentido, procuraremos resgatar a memória de uma pessoa que participou das ocupações de uma escola estadual em 2015.

A reorganização de unidades escolares é uma política pública já aplicada no Brasil. Houve uma muito similar em São Paulo, em 1995, mas a reação, observada em 2015, pelos estudantes secundaristas, foi inédita; por isso, a importância de serem preservados as impressões dos que estavam sendo afetados pela política pública, bem como submeter tais relatos à análise discursiva. Ao ouvir estas vozes, temos uma imagem/visão mais ampla do fenômeno em pauta, lembrando que 
neste artigo o maior objetivo é apresentar de forma reduzida os sentidos da memória de uma mãe de aluno, que também participou das ocupações.

\title{
10 fato e a memória
}

O Estado de São Paulo esteve diante de um movimento rápido que poderia passar despercebido se pesquisadores, em geral, não tivessem o cuidado de registrar detalhes desse momento que foram as ocupações das escolas públicas do Estado de São Paulo em 2015. Os estudos a respeito do objeto têm trazido luz aos atores, às falas, à realidade histórico-educacional que os envolvia.

Jacques Le Goff, na obra História e Memória (1996, p. 477) diz que “A memória, onde cresce a história, que por sua vez a alimenta, procura salvar o passado para servir o presente e o futuro [...]". Com base neste conceito, entende-se que o texto que será registrado e analisado no presente artigo oferecerá suporte à construção da consciência histórica sobre o evento educacional em destaque.

Neste sentido, conforme explicado no resumo, foi escolhida uma entrevista que nos auxilia na reflexão acerca da contraposição discursiva existente entre os que ocupavam as escolas e os que queriam reorganizá-las. Sabe-se que o fato foi divulgado, tomou alguma proporção midiática, porém, em poucos momentos foi evidenciado o discurso dos que estavam sendo afetados pela política educacional. Por certo, a memória ficava distorcida ou limitada. Para sanar tal incompletude, coubenos conhecer e declarar o duplo senso a partir dos questionamentos a seguir: Por que as formações discursivas concorriam entre si? Que efeitos de sentidos de educação podem ser resgatados a partir da discursividade dessa mãe de aluno?

\section{Princípios da análise do discurso}

Segundo Orlandi (2015, p. 13):

\begin{abstract}
A análise do discurso, como seu próprio nome indica, não trata da língua, não trata da gramática, embora todas essas coisas lhe interessem. Ela trata do discurso. E a palavra discurso, etimologicamente, tem em si a ideia de curso, de percurso, de correr por, de movimento. O discurso é assim palavra em movimento, prática de linguagem: com o estudo do discurso observa-se o homem falando. $\mathrm{Na}$ análise do discurso, procura-se compreender a língua fazendo sentido, enquanto trabalho simbólico, parte do trabalho social geral, constitutivo do homem e da sua história.
\end{abstract}

Com efeito, este estudo trará um "gesto de leitura", procurando analisar e registrar a memória de um sujeito envolvido no processo de reorganização e das ocupações das escolas públicas do Estado de São Paulo. Como descrito, teremos por base o instrumental teórico da AD que, 
segundo Leda Vardiani Tfouni e Filomena Elaine Assolini no artigo "Gestos de interpretação e de autoria em producoões linguisticas orais e escritas: desafios e possibilidades ${ }^{3}$ " [...] procura compreender como o objeto simbólico produz sentidos, não a partir de um gesto automático de decodificação, mas como um procedimento que desvenda a historicidade contida na linguagem, em seus mecanismos imaginários".

Pêcheux em "Ler o arquivo hoje" (2010) relata que não existe interpretação absoluta. Para ele, a leitura é múltipla, pois diferentes discursos atravessam a realidade. Na prática, tal análise se apresenta como um olhar possível no sentido de conhecer o que é autêntico na perspectiva dos que ocupavam as escolas.

Orlandi (2007, p. 54) afirma que há materialidade histórica inscrita no texto e esta é sustentada pela posição que os sujeitos ocupam na sociedade. Com efeito, serão considerados nesse procedimento analítico discursivo os aspectos históricos produzidos durante as ocupações os quais, segundo Orlandi (2007, p. 24), advém da compreensão individual e global do acontecimento, traduzida em memória, sob bases ideológicas. Face a qualquer objeto simbólico, o sujeito é obrigado a interpretar e isso se traduz em significar, ou melhor, o sujeito interpreta a partir de uma impressão que é dada pela ideologia.

A mesma autora diz que em $\mathrm{AD}$ a compreensão do sujeito não é a de um sujeito físico, empírico, sociológico, que existe a priori, mas de um sujeito que se constrói no discurso. Os sujeitos assumem uma posição-sujeito. Dessa forma, são consideradas as imagens factuais que os sujeitos produzem de si mesmos e dos seus interlocutores e da realidade que os cerca. As situações de fala são regidas por essas imagens.

Para a AD, a identidade é sempre móvel, está em constante transformação; o sujeito é constitutivamente heterogêneo, mas em situação de entrevista, ele assume posições e retoma sentidos preexistentes para formar o discurso e fica registrado o momento. Dessa forma, explicita-se que $o$ corpus da análise foi constituído por entrevistas agendadas com os participantes das ocupações identificados pelo Facebook, Mídia Ninja, Jornal da Região do $\mathrm{ABC}$ e, coletivamente, durante o Congresso que tratou desse objeto de estudo.

Ressalta-se que, de forma diferenciada, foram ouvidos estudantes, famílias, gestor escolar e Estado. Uns foram situados na ideia dos locutores, outros dos enunciadores e outros dos autores. Em face dos relatos, duas questões iniciais embasaram a análise: a primeira, por que as formações discursivas concorriam entre si e a segunda, quais efeitos de sentidos de educação podem ser resgatados a partir de um discurso?

Orlandi (2007, p. 24) diz que as pessoas do discurso são: autores, os locutores e os enunciadores. Oswald Ducrot (1980) distingue os três. O locutor se apresenta como o "eu" no discurso; 
o enunciador apresenta uma perspectiva já construída e o autor é aquele que se relaciona com o contexto sócio histórico, emitindo um discurso relacionado com a exterioridade, e há participação efetiva dele no exterior, ou seja, o autor transpõe a dimensão do eu e do outro, considera o nós institucional, por isso compreende uma relação de pertencimento e de inclusão na realidade. Nosso entrevistado se situa na posição de locutor, mas também na de autor.

Orlandi (2007, p. 54) afirma que a materialidade histórica inscrita no texto é sustentada, entre outros aspectos, pela posição-sujeito assumida na construção do discurso de autoria, conferindo ao autor uma identidade social.

\section{As contradições discursivas}

Para T. A. Van Dijk em Discurso e Poder (2004), compreender as linguagens dos protestos e a relação sociolinguística estabelecida entre aqueles que estão em um debate político, é fator determinante para tomada de posição dos membros de uma sociedade sobre um dado impasse temático. Para o autor, existe a linguagem simbólica da elite que denota e almeja controle cognitivo e ideológico das massas e cujo sentido precisa ser desvendado, principalmente pelos que protestam para que possam resistir com propriedade ao ideário controlador. No caso da reorganização, o discurso sobre um possível gerenciamento de cunho financeiro devido à crescente evasão escolar não fora veiculado pela SEE/SP. Bem longe disso, reproduziam que as escolas estavam esvaziadas por redução de natalidade e que não era adequado ao estado manter escolas sem demanda. Tais conclusões não vieram apenas pelo relatado nas entrevistas, houve outros documentos, mas aquelas certamente contribuíram para a melhor composição da cena. Ademais, ressaltamos que os discursos daqueles que sofrem o controle, ou melhor, a dominação, são importantes para uma sociedade que se deseja democrática. A apresentação do discurso do que sofre o controle é importante em uma sociedade que se diz democrática. Com efeito, a entrevista com a mãe do estudante deu-nos a possibilidade de comparar e de conhecer as contradições discursivas desse cenário conflitante e de traduzir a linguagem subjacente à ação governamental.

Sintetizando, diante do contido nos documentos e nos relatos, partimos da hipótese de que as discursividades sobre o assunto reorganização/ocupações das escolas públicas do Estado de São Paulo operavam numa certa tensão entre os argumentos refutáveis da SEE/SP e as inquietações daqueles que se propuseram a subverter a ordem imposta. No percurso, percebemos que, de fato, o impasse se instaurou porque os representantes governamentais agiram intempestivamente, valendo-se do "poder/autoridade", desconsiderando os interesses e as necessidades dos estudantes dessa rede, com a finalidade de reduzir o papel que precisam desempenhar com a Educação, principalmente quando tomaram por prática efetiva fechar/disponibilizar 200 escolas. Os jovens e 
apoiadores, por sua vez, não se sentiram intimidados e ocuparam algumas unidades escolares. Pela resistência de base comunicativa exercida entre os jovens, aos poucos o discurso persuasivo/manipulador, comum aos órgãos públicos regidos pelo conceito neoliberal, foi sendo desconstruído, perdeu força e a reorganização foi invalidada legalmente.

\section{Os movimentos estudantis e a produção de discursos}

Desde 1960 os movimentos estudantis se destacam no cenário social. Há um histórico de manifestações que ganhou mais força nas últimas décadas do século XX e continua sendo referência de ação política no século XXI. Em 2011, o Ocuppy W all Street foi um exemplo de organização jovem em prol da ética, da moral, e do resgate à justiça social (GOHN, 2013). No Chile em 2006, na Argentina em 2011; e no Brasil, no estado do Mato Grosso, em 2012, estudantes da Educação Básica ocuparam as escolas. Essa ação foi retomada em 2015 em São Paulo e em 2016 nas escolas do Sul, do Centro-Oeste e do Nordeste brasileiro.

Os secundaristas, diante dos desafios impostos pela realidade vivida, aderiram a uma forma de interação que vem sendo utilizada nos movimentos do século XXI. Materializou-se entre eles, no período anterior e durante as ocupações, o estético-discursivo de veiculação em rede, que se pauta na objetividade e na construção de acordos rápidos em prol do tema que colocam em debate. A base da ação político-discursiva foi o documento encaminhado pelo coletivo O Mal-Educado; nele estavam descritas as experiências anteriores de luta dos estudantes de outros países da América Latina. Tais informações deram o tom ao movimento.

O documento foi amplamente divulgado. A partir dele, os jovens conversaram com seus pares, professores e outros apoiadores e tomaram a decisão de aderir ao movimento. Ao longo do processo, após ocupadas as escolas, de forma paulatina, os participantes mantiveram o diálogo por meio de WhatsApp etc. Ou seja, entre eles houve a interlocução que não foi possível com os representantes da SEE/SP. Observa-se que um acontecimento nesses termos não foi exaustivamente planejado, mas foi alvo de processos de leitura e de muito diálogo. Percebe-se ainda que as ocupações poderiam não ter ocorrido se houvesse interação face a face com os que estavam na outra ponta do "cabo de força".

Há "regras anônimas que definem as condições de existência desses acontecimentos discursivos" que movimentam a história (GREGOLIN, 2001, p. 17). Buscou-se entender, em alguma medida, o que tornou possível "a emergência desses objetos do discurso" (Idem, Ibidem) entre os manifestantes, pois essa reflexão também é problemática e fundamental para a AD.

Chegamos à compreensão que existia um locutor em espaço privilegiado e não acessível à interlocução, por isso a reação dos jovens, que não se tratava de uma rotina, nem mesmo de uma 
estratégia muito bem elaborada, mas muito dialógica. À decisão de reorganizar, sem interlocução possível, desencadeia-se a ação de ocupar, neste caso, com plena interlocução, constituída no bojo das relações políticas que visam a transformação social, dando total vazão aos processos discursivos voltados à ideia de democracia. (PÊCHEUX, 2006, p. 191).

A SEE/SP tomou a decisão e não dialogou. Eles se perguntavam, atônitos: - O Estado pode fazer isso? Essa foi uma questão recorrente que ecoou nas redes sociais dos estudantes. Foi por essa linha reflexiva que a mãe discursou, como veremos após a explanação sobre a metodologia AD.

\section{A metodologia da AD na entrevista em pauta}

Analisar é se desdobrar na relação entre descrição e interpretação. De acordo com Pêcheux (2002, p. 54), "toda descrição abre sobre a interpretação", para que “através das descrições regulares de montagens discursivas, se possam detectar os momentos de intepretações enquanto atos que surgem como tomadas de posição reconhecidas como tais, isto é, como efeitos de identificação assumidos e não negados" (idem, p. 57). Para Pêcheux (idem, ibidem), a interpretação é "uma questão de ética e política: uma questão de responsabilidade”. Como exemplo dessa interpretação, pode-se pensar sobre os termos invasões e ocupações. No início do movimento estudantil, muitos relatos utilizavam o termo invasões das escolas, mas eram corrigidos para ocupações. Esse mesmo problema esteve presente durante o Movimento dos Sem Terra (MST). Fernandes (2008, p. 12 e 13) analisando os termos dentro da realidade social apresentada diz:

[...] Para exemplificar essas considerações, observemos o emprego dos substantivos ocupação e invasão em revistas e jornais que circulam em nosso cotidiano. Tais substantivos são constantemente encontrados em reportagens e/ou entrevistas que versam sobre os movimentos dos trabalhadores rurais Sem-Terra e revelam diferentes discursos que se opõem e se contestam. Em torno do Sem Terra, ocupação é empregado pelos próprios Sem-Terra, e por aqueles que os apoiam e os defendem, para designar a utilização de algo obsoleto, até então não utilizado, no caso, a terra. Invasão, referindo-se à mesma ação, é empregado por aqueles que se opõem aos Sem-Terra, contestam-nos, e designa um ato ilegal, considera os sujeitos em questão como criminosos, invasores. As escolhas lexicais e seu uso revelam a presença de ideologias que se opõem, revelando igualmente a presença de diferentes discursos, que, por sua vez, expressam a posição de grupos de sujeitos acerca de um mesmo tema. Integrante da noção de discurso, encontra-se a noção de sentido compreendida como um efeito de sentidos entre sujeitos em interlocução (sujeitos se manifestando por meio do uso da linguagem). Assim, ocupação e invasão, nos discursos supracitados, vão além de seus significados prescritos nos dicionários. Se observarmos, por exemplo, a significação de invasão para ambos os grupos de sujeito (os defensores e os contestadores do Sem-Terra) veremos que invadir tem sentidos diferentes e peculiares para esses sujeitos. Esses sentidos, e não o significado da palavra apenas, são produzidos em decorrência da ideologia dos sujeitos em questão, da forma como compreendem a realidade política e social na qual estão inseridos. Para falarmos em discurso, precisamos considerar os elementos que têm existência no social, as ideologias, a História. 
Esse modelo de interpretação é, então, o aspecto metodológico a ser contemplado no presente artigo. Seguiremos apenas três etapas do método analítico: selecionaremos alguns enunciados do discurso escolhido, a posição do enunciador em face do ocorrido e registraremos a análise desses enunciados. Na perspectiva discursiva, o corpus é constituído a partir de um "recorte" possibilitando, desse modo, uma leitura não subjetiva dos discursos, pois traz uma imagem real do locutor/autor; dessa forma, este será composto de um "universo discursivo" repleto de sentidos político-sociais (MAINGUENEAU, 1993, p. 116).

Pêcheux (2006, p. 29-32) faz uma distinção do discurso como "estrutura" e do discurso como "acontecimento". O discurso como estrutura constitui-se em espaços "logicamente estabilizados” por suas características estruturais próprias das ciências exatas e biológicas. Já o discurso como acontecimento pode apresentar uma estabilidade relativa ou simplesmente não a apresentar, uma vez que se constitui num espaço estrutural das humanidades, ou seja, "todo discurso marca a possibilidade de uma desestruturação-reestruturação dessas redes e trajetos: todo discurso é o índice potencial de uma agitação nas filiações sócio históricas de identificação" (idem, p. 56).

Para Pêcheux (2006, p. 160), a evidência de "sentido" na linguagem é um efeito ideológico determinado pela "formação discursiva". Trata-se do "efeito de sentido" (idem, p. 164) em maior ou menor preponderância. Assim, o sentido:

\begin{abstract}
de uma mesma palavra, uma expressão e uma proposição podem receber sentidos diferentes - todos igualmente "evidentes" - conforme se refiram a esta ou aquela formação discursiva, é porque - vamos repetir - uma palavra, uma expressão ou uma proposição não tem um sentido que lhe seria "próprio", vinculado a sua literalidade. Ao contrário, seu sentido se constitui em cada formação discursiva, nas relações que tais palavras, expressões ou proposições mantêm com outras palavras, expressões ou proposições da mesma formação discursiva (PÊCHEUX, 2006, p. 164)
\end{abstract}

Pêcheux (idem, p. 92), para referir-se ao mecanismo de produção dos discursos, cunha o conceito de "processos discursivos". Conforme o autor: "processos discursivos" diferenciados têm como base comum a língua e se desenvolvem a partir das leis internas de um determinado sistema linguístico. Indiferentemente da classe social a qual o "indivíduo" pertença e das crenças que possua, o sistema linguístico é o mesmo utilizado por "indivíduos" situados em diferentes estratos sociais. Já a materialização linguística da "fala" do sujeito se dá no "intradiscurso", ou seja, no "funcionamento do discurso, em relação a si mesmo", sendo este "um efeito reflexivo, no interior do próprio interdiscurso" (PÊCHEUX, 2006, p. 167). Pois, ao falar, o sujeito deixa "rastros" linguísticos a partir dos quais se constrói uma aparente evidência de sentido. É no intradiscurso, "fio discursivo" (idem, ibidem) que se obtém as condições para as análises discursivas.

Os efeitos da história na língua promovem um deslocamento semântico constante na constituição dos sentidos: fazendo-os apenas próximos, mas nunca idênticos ao original - isso porque 
o momento histórico de sua produção é sempre outro. Assim, esse processo discursivo se dá numa tensão constante entre o "Mesmo e o Outro".

Entra-se, portanto, na ideia de interdiscurso (PÊCHEUX, 1999, p. 102) e consequentemente, de pré-construção de imagens ${ }^{5}$ (idem, p. 51) que se aproximam da noção de senso comum, ou seja, daquilo "que todo mundo sabe", colocando em confronto o pensamento particular com o que é de fato provado no discurso do outro, em termos lacanianos (idem, p. 133), aquele discurso que serve de referência para o sujeito enunciador no processo de identificação resultando, fatalmente, na sua interpelação.

\subsection{Alguns efeitos de sentido produridos pelo/ no discurso do sujeito mãe}

Sendo o nosso objeto de análise a entrevista sobre o processo de reorganização/ocupação das escolas públicas do Estado de São Paulo, o objetivo se concentra em analisar o discurso do ator envolvido nesse processo buscando, assim, o reconhecimento dos "efeitos de sentido" (PÊCHEUX, 1999, p. 164) desse discurso na (re)construção da(s) identidade(s) (HALL, 2000) ou "identificação" (ORLANDI, 2001) dos estudantes da Rede Estadual de Educação Básica de São Paulo.

O sujeito da entrevista é Arlete, mãe do estudante Guilherme. O jovem é aluno da terceira série do Ensino Médio e participou das ocupações juntamente com a mãe. Com o processo de reorganização, Guilherme sairia da escola em que estudava, em frente à sua casa em São Paulo e seria alocado em outra escola da rede pública localizada a pouco mais de 30 minutos de sua residência. O tempo de caminhada em si não se configurava como empecilho, mas a vulnerabilidade dessa região, sim. Cabe ainda ressaltar que nesse raio de abrangência há registros de três escolas que foram ocupadas, sendo uma em Santo André - EE VBG - e duas em São Paulo: EE VFP o e EE S. ${ }^{6}$

\subsection{A entrevista}

Solicitada pela entrevistadora a falar sobre a reorganização e as ocupações das escolas públicas no estado de São Paulo, a entrevistada desabafa:

$$
\mathrm{R} 1=\mathrm{Da} \text { noite para o dia eles desalojaram meu filho. } .
$$

O sujeito em R1 apresenta em seu discurso sinais de insatisfação, indignação diante da forma como se deu o processo de reorganização e as ocupações das escolas públicas no Estado de São Paulo. Tal insatisfação pode ter raízes no discurso institucionalizado do Estado de contenção de gastos, ou mesmo falta de política pública para lidar com a crescente evasão escolar. A expressão 
"Da noite para o dia" demonstra a forma abrupta e arbitrária com que se deu o ocorrido, de cima para baixo, sem uma preparação, de supetão, sem que ninguém esperasse.

O cenário denota, conforme observado na fala da mãe, que a educação brasileira convive com leis pautadas no ideário democrático, porém, na prática, impera o autoritarismo e as políticas neoliberais. Com efeito, não há como atender o duplo foco, pois são contraditórios, o que resulta em opressão e para fugir dela, povo precisa estar em constante alerta para fazer valer seus direitos. A mãe indignada repete:

$$
\text { R2 = eles desalojaram meu filho (grifo nosso) }
$$

O pronome pessoal de terceira pessoa do plural - eles - assume aqui uma (re)configuração especial. "Eles" é entendido como o "Não nós", os outros. Eles - o Estado pluralizado nos sujeitos institucionalizados "desalojaram meu filho".

O verbo desalojar significa "tirar do alojamento; fazer sair de um posto; tirar do lugar onde estava" (NASCENTE, 2000). O sujeito mãe produz, nesse momento, um efeito de sentido de uso de força, mesmo que simbólica, do ato praticado pelo Estado. Ainda mais se levarmos em conta a expressão anterior "Da noite para o dia”, isto é, abruptamente, "eles”, os burocratas, "desalojaram”, isto é, tiraram o "meu filho" de onde ele estava. O uso do pronome meu estabelece aqui uma relação não de posse, mas de intimidade, maternidade, carinho etc. contrastando completamente com o eles, tão distante, tão outro, tão além. Segundo Orlandi (2001, p. 100), "na relação discursiva são as imagens que constituem as diferentes posições", uma vez que "as identidades resultam desses processos de identificação em que o imaginário tem sua eficácia”.

Ao se posicionar dessa forma, o sujeito do discurso atribui ao Estado a responsabilidade por desalojar "meu filho" deixando, em seus rastros discursivos, marcas que estabelecem uma relação negativa com o Eles do discurso. Essa negatividade, no posicionamento desse sujeito, pode ser entendida como um efeito dos discursos relacionados à contenção de gastos públicos, que ganham autoridade no neoliberalismo, o qual valida um projeto excludente, por isso contra a ideia de educação como direito de todos.

Ainda sobre o sujeito mãe, questionada sobre o porquê da sua participação na ocupação da escola, a entrevistada assim se posiciona:

R3 =O que me fez participar dessas ocupações e permitir que meu filho participasse foi porque, da noite para o dia, desalojaram meu filho da segunda casa dele para jogar para qualquer lugar... sem comunicar para a comunidade, sem perguntar se aquilo era bom ou não era. 
Observa-se no R3 que o sujeito assume sua posição de protagonista do discurso. O pronome oblíquo Me é identificador de um pronome de primeira pessoa do singular Eu. Quem diz Eu se assume enquanto sujeito do discurso, o Eu ancora o texto dando um caráter referenciado, desvelando a ilusão referencial. O Eu produz um efeito de aproximação, de subjetividade da linguagem (FIORIN, 2002). No recorte efetuado dentro do recorte acima temos "O que Me fez participar dessas ocupações e permitir que Meu filho participasse [...] (grifos nossos)"; O Me e o Meu - pronomes - atribuem ao discurso um efeito de autoria, de posicionamento consciente di-

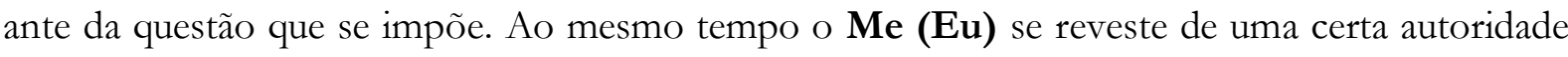
discursiva por "permitir que meu filho participasse". Efeitos de sentido de autoridade, de consciência cidadã, de engajamento político social.

Tal posicionamento tem a pretensão de ser reforçado, sustentado, legitimado quando o sujeito repete que "foi porque, da noite para o dia desalojaram Meu filho", acrescentando: "da segunda casa dele para jogar para qualquer lugar". O sujeito qualifica aqui a escola como uma "segunda casa dele", talvez porque Guilherme tenha sempre estudado naquela escola e se identifica com ela, tem um laço fraterno, de grande afetividade, com a escola, os colegas, funcionários, professores etc. Ainda, a complementação do recorte anterior "da segunda casa dele para jogar para qualquer lugar" (grifo nosso) demonstra um certo tom de revolta para com o Eles citado no discurso, "jogar" aqui possui a conotação de que o Eles (o Estado) trata os estudantes como se fossem objetos que podem ser jogados para "qualquer lugar", não um lugar determinado, mas qualquer. Isto é, "desalojaram" "meu filho", tiraram-no do lugar em que ele estava que era a "segunda casa dele" para o "jogar em qualquer lugar"

Torna-se urgente a estruturação de novas bases escolares; todavia, esse anseio da juventude tem sido sufocado pela política econômica neoliberal que promove a estagnação das nações periféricas com a ideia de educação mínima. A educação brasileira, por exemplo, sempre sofreu a interferência do capital e das leis globais, por isso tem passado por constantes processos de "mudanças" sem participação dos professores, alunos e sociedade.

O discurso contido nos recortes em análise revela um "poder" produzido e exercido pela SEE/SP que reduz seu papel de formadora dos jovens estudantes. O Sujeito em R3, apresenta marcas discursivas que deixam rastros de indignação e revolta. Essa indignação se faz presente no recorte "sem comunicar para a comunidade, sem perguntar se aquilo era bom ou não era". Tais sentimentos da mulher-mãe nos leva ao binômio superioridade/inferioridade, uma vez que esse ideal de educação vem sendo apresentado aos sujeitos como norma e cabe ao povo (estudantes) aceitar essas normas, pois o Estado é o detentor do poder e por isso pode não "comunicar para a comunidade" suas decisões, mesmo que isso a afete, "sem perguntar se aquilo era bom ou não era", 
tendo em vista que já está posto, cabendo-lhes apenas o aceite, a submissão às ordens do Estado. É possível observar no intradiscurso certa tensão desse sujeito em relação ao processo de reorganização/ocupação das escolas públicas no estado de São Paulo.

R4 = Da noite para o dia simplesmente deram um papel assim - isso aqui é para você fazer cartinha de ônibus. Ele perguntou: - Por quê? Se eu moro aqui em frente à escola?

O discurso da imposição do Estado em relação ao processo de reorganização das escolas no estado de São Paulo se reconfigura e se materializa, naturalizando as "formações discursivas" da ordem. Em R4 lemos "Da noite para o dia simplesmente deram um papel assim..." O não assujeitamento desse sujeito ao interdiscurso do Estado concretiza-se em seu "intradiscurso" por meio da expressão "Da noite para o dia simplesmente deram um papel assim" o que reforça, reafirma o discurso contido em R3 "da noite para o dia desalojaram meu filho". A expressão "da noite para o dia" é significativa, prenhe de sentidos e denúncia da arbitrariedade ocorrida, pois eles (o Estado) “... sem comunicar para a comunidade, sem perguntar se aquilo era bom ou não era” impõe seu projeto tido como ideal "sem comunicar", "sem perguntar" aos atores principais. Ao mesmo tempo, esse discurso cobra das autoridades uma ação transparente, dizendo que "queremos ser ouvidos", porque isso nos afeta.

R5 = Disseram ainda: - seus pais vêm aqui para que possam escolher qual escola vocês querem que você fique, porque não vai ficar mais aqui. Aqui não vai mais existir.

Os discursos contidos em R5 são representativos das relações de poder e manutenção de domínio, por isso, considerado um acontecimento. Se de um lado se evidencia a violência simbólica, em contrapartida, há também um discurso que reivindica a legitimação da identidade, de diálogo, que é a questão central.

O modelo capitalista vigente impõe novas estratégias e artefatos na produção das práticas sociais, viabilizando outros saberes e novos poderes, mantendo as táticas de controle e de domínio por intermédio de outros mecanismos, visando a diferentes grupos sociais.

Quando a entrevistada usa da expressão "Disseram ainda" ela delega a fala ao Eles do discurso discutido anteriormente (o Estado). $\mathrm{O}$ verbo no pretérito perfeito do modo indicativo marca uma relação de anterioridade entre o momento do acontecimento e o momento de referência presente (FIORIN, 2000). O verbo "disseram" seguido do advérbio "ainda" combina traços temporais e aspectuais. "Ainda" contém os traços de anterioridade (pressuposto) e inacabado (posto). "Por isso, significa que o enunciador pressupõe que um fato ocorreria num momento posterior a 
um dado momento e afirma que é concomitante e acabado em relação a um determinado ponto de referência" (FIORIN, 2000, p. 171).

$\mathrm{Na}$ expressão "seus pais vêm aqui para que possam escolher qual escola vocês querem que você fique, porque não vai ficar mais aqui. Aqui não vai mais existir" caberia uma reflexão foucaultiana sobre a função do Estado. Para Foucault (2004), é precisamente isso, a vigilância hierárquica, o olhar sempre presente do Estado, por meio de seus representantes (Eles), para quem os vários sistemas de agrupamento tornam mais fácil o controle dos corpos, como a separação de salas de aula ou a formação de filas.

Nos atuais sistemas de educação, os burocratas e funcionários das Secretarias Estaduais fiscalizam e asseguram que os procedimentos escolares, administrativos e pedagógicos estejam em concordância com aquilo que está estabelecido nas normas. Todo o Estado é formado necessariamente por mecanismos em que um nível hierárquico se responsabiliza pela fiscalização de si mesmo e também por aquele que lhe é imediatamente inferior.

O discurso da imposição do Estado em relação ao processo de reorganização das escolas no estado de São Paulo mais uma vez se reconfigura e se materializa naturalizando as "formações discursivas" da ordem. Em "seus pais vêm aqui para que possam escolher qual escola eles querem que você fique" observa-se que ao estudante não é permitido escolher, tirando-lhe o direito cidadão. Sendo ele o principal autor de todo o processo de reorganização/ocupação das escolas, não lhe é dado vez nem voz.

Tiram-lhe a voz, o direito de opinar, de escolher e ainda lhe tiram o lugar reafirmando, corroborando o exposto anteriormente na análise quando o sujeito mãe diz que "da noite para o dia desalojaram meu filho da segunda casa dele para jogar para qualquer lugar". A carga semântica do verbo elidido "desalojaram" significa mais, possui um novo efeito de sentido quando "Eles" afirmam que "Aqui não vai mais existir".

A instituição Estado, em maior ou menor escala, sempre buscou criar mecanismos de exclusão. Em sua obra Vigiar e Punir (2014, p. 31), Foucault declara que a instituição é um corpo desenhado a partir do "[...] conjunto de elementos materiais e das técnicas de armas, de reforço, de vias de comunicação e de pontos de apoio para as relações de poder e de saber que investem os corpos humanos e os submetem fazendo deles objetos de saber". Trata-se de uma rede de relações que não se esgotam, cujo movimento se dá por aquilo que o autor denomina microfísica do poder, presente nas instituições e aparelhos, em que os corpos são submetidos por processos estratégicos de controle, de forma a possibilitar diferentes domínios que garantam, na medida do possível, um exercício de poder para conservação da classe dominante. (FOUCAULT, 2014, p. 30) 
Os processos estratégicos de poder se manifestam por um conjunto de artefatos que demarcam a regularidade e os ajustes sociais - tal como as leis do Estado. Estas, por sua vez, são parte das práticas exercidas sobre a sociedade como um todo, a partir de discursos que fomentam estratégias e mecanismos de controle capazes de criar verdades. Esse estudo traz um exemplo dessa forma de governo e de uma forma de reação. Lembramos que aconteceram em 2016 outras ocupações por todo o país em repúdio à PEC 241 e à MP nº 746.

R6 = Não pode ser! Aqui não seria mais VFP seria JS. Por que eles iam trocar de Valdir para Joaquim Suarez? Tirar os alunos de lá para passar para cá? A Joaquim estava deteriorada. Se a escola tá ruim arruma. Por que desalojar meu filho que está aqui desde a primeira série do primário. E trazer de lá para cá? Por quê?

Os discursos produzidos pelo Estado em determinados contextos visam a fixar o homem em modelos de docilidade e produtividade (FOUCAULT, 2006, p. 206). A reorganização, advinda de uma política de Estado, segundo se observa nos recortes da entrevista, seria capaz de transformar o cidadão em objeto que "da noite para o dia" o "desalojar" e o "jogar para qualquer lugar". O inconformismo do sujeito mãe expresso em "Não pode ser!" é característico da inquietação diante da ação injusta. "De cima para baixo, sem perguntar se aquilo era bom ou não". Não se deve interrogar a própria lei? A origem, a justificativa, a operacionalidade?

Em “Aqui não seria mais EE VFP, teria o nome de EE J.S. Por que eles iam trocar o nome da escola? Tirar os alunos de lá para passar para cá? A JS estava deteriorada, era de lata. Se a escola tá ruim arruma". A escola de Guilherme, além de não atender mais ao Ensino Médio, mudaria de nome? Eles (o Estado) "iam acabar com a história da EE VFP, que foi conquistada por nós em 1988". Reafirmando mais uma vez o discurso autoritário da SEE/SP e o papel subserviente da sociedade em somente acatar, obedecer ao que lhe é imposto.

O poder é uma forma ardilosa de articular a sociedade. Trata-se de uma engrenagem complexa que envolve leis, governos, comportamentos, entre outros. Tudo se dá por meio de práticas sociais que produzem uma linguagem própria com vistas à manutenção de propósitos nem sempre bons para o todo social.

Quando questionada pela entrevistadora: "Há outras escolas perto da EE VFP?", o sujeito entrevistado assim se manifesta:

R7 = Não. De Ensino Médio não tem. Para quem mora na Fazenda da Juta e Mascarenhas de Moraes não há outra escola de Ensino Médio próxima. Depois daqui só a EE N., a EE A e a EE S. Não tem como ficar se locomovendo se ele está aqui em frente. Por que não terá Ensino Médio aqui? A gente acha um absurdo. Eu acho! 
Seu discurso registrado no recorte acima é uma forma de justificar sua aversão ao projeto de reorganização das escolas públicas do Estado de São Paulo, em especial a ação inexplicável que teriam com a EE VFP que era a segunda casa de seu filho.

Os saberes do Estado são ditados pelos poderes que esquadrinham o sujeito/comunidade acadêmica por meio de rituais políticos de certo tipo de assujeitamento que, por vezes, são requalificados, surgindo novas técnicas e/ou nomenclatura, tal como "reorganização". Consequentemente, buscam-se novas estratégias de dominação que, à primeira vista, aparecem por meios de efetivação da garantia de um sujeito de direito, mas que, na verdade:

O que se procura nessa técnica [...] não é tanto o sujeito de direito, que se encontra preso nos interesses fundamentais do pacto social; é o sujeito obediente, o indivíduo sujeito a hábitos, regras, ordens; uma autoridade que se exerce continuamente sobre ele e em torno dele, e que ele deve deixar funcionar automaticamente nele (FOUCAULT, 2014, p. 128).

Ao ser questionada sobre "Como foram os dias de ocupações?", obteve-se a seguinte resposta:

R8 = Foi tudo organizado. Tinha uma lista de entrada de presença e, também, de saída. Não era qualquer pessoa que entrava na escola. Foram feitas reuniões com os pais. Tudo anotadinho. Tudo certinho. Nada do que tinha na escola foi mexido. O que era da escola. O que era da escola ficou na sala de aula. Os pais levavam alimentos o meu filho Guilherme participou. Tentávamos convencer os pais a apoiar nossa causa. Essa é a única escola de Ensino Médio da região e não podia fechar.

Em R8 o sujeito passa a descrever como foi o movimento de ocupação da escola em epígrafe dizendo que "Foi tudo organizado", com "lista de entrada" e "também de saída" como forma de reforçar o movimento, de apoiar a ação, de elogiar. Diante de todos os argumentos colocados pelo sujeito/mãe, ela sinaliza que "Essa é a única escola de Ensino Médio da região e não podia fechar”, explicando aí o motivo do movimento e sua justificativa.

A materialidade linguística "Tudo anotadinho. Tudo certinho", por sua vez, reporta à análise do excerto "Foi tudo organizado", reforçando aí a importância do movimento de ocupação das escolas por parte dos alunos. Para Foucault (2002): “[...] por mais que o discurso seja aparentemente bem pouca coisa, as interdições que o atingem revelam logo, rapidamente, sua ligação com o desejo e com o poder"; no caso do discurso em epígrafe, o desejo de que o movimento seja reconhecido como legítimo e legal e, consequentemente, o poder de enunciar como o outro, o discurso do povo, contra o discurso do Estado.

A expressão linguística "Os pais levavam alimentos" é uma forma de reforçar a importância do movimento, já que se sustenta nas relações de forças travadas na exterioridade, resultante da “constituição da nossa sociedade e relações de hierarquia, sustentadas no poder desses lugares na 
interlocução" (ORLANDI, 2001, p. 39-40). O sujeito entrevistado tenta aqui legitimar o movimento que conta com a adesão dos pais, o que acaba sendo corroborado pela materialidade linguística "Tentávamos convencer os pais a apoiar nossa causa". Esse tipo de discurso, cuja formação deixa transparecer a cobrança de responsabilidades para com a vida acadêmica do filho, relacionase com o discurso da responsabilidade social e da cidadania.

\begin{abstract}
R9 = Fizemos tudo isso, ele finalizou em 2016 a segunda série do Ensino Médio na EE VFP, mas em 2017 foi transferido para a EE S., fecharam o Ensino Médio mesmo na escola que ele estudou desde o primeiro ano do Ensino Fundamental. Fez a terceira série do Ensino Médio em 2017 na EE S. Aqui só tinha duas salas de Ensino Médio, os professores mais faltavam do que vinham. Os estudantes tinham 2 ou 3 aulas por dia. Os professores tinham medo do lugar perigoso. Por que não abriu vagas no noturno? Disseram que o sistema não aceita! Disseram que tem que estar com documentos em ordem para ser matriculado no noturno. Na escola era o argumento sempre usado. Ele foi para uma escola que tem que tomar dois ônibus. Só pode estudar a noite se estiver trabalhando? O João, meu vizinho da idade do Guilherme fica andando de skate na quadra. Parece que desistiu de estudar depois da mudança de escola.
\end{abstract}

Em R9 temos o excerto "Fizemos tudo isso, ele finalizou em 2016 a segunda série do Ensino Médio na EE VFP, mas em 2017 foi transferido para a EE S., fecharam o Ensino Médio mesmo na escola que ele estudou desde o primeiro ano do ensino fundamental”. A forma verbal “fizemos" elidido no pretérito perfeito do modo indicativo expressa uma ação totalmente concluída. O efeito de sentido que esse verbo expressa é o de acabamento da ação, de conclusão, de uma ação pontual: "ele finalizou” reforça o término dessa ação. A conjunção adversativa MAS, introduz algo inesperado. Apesar de todo o movimento político dos alunos e comunidade, "em 2017 foi transferido para a EE Sapopemba, fecharam o Ensino Médio mesmo na escola que ele estudou desde o primeiro ano do ensino fundamental".

Os discursos, montados por meio de diferentes ordens, trazem consigo "verdades" ou "mentiras", com características de "ensinamento" ou de "engano", de "acolhida" ou de "desprezo", para semear esperança ou matá-la, sob a propositura de sobreviver e repassar um determinado grau relativo de poder.

As palavras, no conjunto ou isoladas, possibilitam evidenciar diferentes discursos e a contradição entre eles. De uma forma geral, são muitos os discursos a favor da vida, da dignidade, dos direitos humanos, em defesa da justiça, pela promoção humana e pelo emprego, pela educação, pela sociedade. Contudo, a realidade continua triste e devastadora, deprimente e escandalosa. Quantas palavras vazias! Quantos pronunciamentos sem sentido! Quantos discursos sem nexo! Na prática, tudo é diferente, até contrário. Falta coerência entre o que se diz e o que se faz, entre o prometido e o cumprido. Em suma, sempre houve quem se aproveitasse do poder para enganar os mais simples e mais pobres, enfim, no caso do Brasil, a maioria esmagadora da sociedade. 
R 10 =Muita gente no bairro não gostou das ocupações, mas eu pergunto: - onde seus filhos irão estudar o Ensino Médio? E a preocupação do filho estar longe? Eu não queria ver a EE VFP fechada no noturno.

Em R10, o sujeito do discurso apresenta uma relação de indignação com seus pares quando afirma que "Muita gente no bairro não gostou das ocupações"; a materialidade linguística "Muita gente no bairro" manifesta outros sujeitos que não partilham elementos de saberes comuns, ligados a formações discursivas compatíveis com as dos sujeitos entrevistados. Esse outro discurso evidencia um contradiscurso, de não adesão ou indiferença ao movimento realizado pelos alunos do Estado de São Paulo. Ou seja, muita coisa não muda também por falta de consciência coletiva da realidade. "O João deixou de estudar e fica andando de skate na quadra”. Quem se importa com o João?

Ainda em R10, é possível constatar, pelas marcas discursivas do sujeito, a presença de uma liderança quando se coloca ou questiona alguns episódios: "Fizemos tudo isso", "os professores mais faltavam do que vinham", "Os estudantes tinham 2 ou 3 aulas por dia", "Por que não abriu vagas no noturno? ", "Só pode estudar à noite se estiver trabalhando?". Ao deixar resquícios em seu discurso do perfil de liderança, esse sujeito aponta para uma suposta superioridade da sua condição de mulher e mãe, consciente do que de fato importa ao filho e à sociedade.

No recorte a seguir - R11 - observamos que o Estado de governo já não age por meio da administração de território, mas numa relação instrumental com a população.

R 11 = Quando os alunos do | Ensino Médio noturno ocuparam a escola, a vice-diretora chamou a polícia, disse que estava presa, sequestrada. A polícia não tinha como agir, pois, havia um documento elaborado por um advogado. Ficamos lá, fizemos mutirão para limpar a escola e retrocederam aquele ano, como disse no próximo meu filho saiu de lá. Fecharam o período noturno.

$\mathrm{Na}$ frase "Quando os alunos do Ensino Médio noturno ocuparam a escola, a vice-diretora chamou a polícia", fica evidente, conforme Foucault (2008, p. 145), os procedimentos de controle: primeiro a lei, depois a disciplina, depois a segurança. "A segurança é uma maneira de acrescentar, de fazer funcionar, além dos mecanismos propriamente de segurança, as velhas estruturas da lei e da disciplina", de modo que dispositivos legais e disciplinares estão amplamente presentes na nova disposição de governo.

Quando se utiliza da expressão "disse que estava presa, sequestrada”, o sujeito da entrevista delega a um sujeito - ELA/A VICE-DIRETORA - a responsabilidade da fala "estava presa, sequestrada". Não é a entrevistada quem diz que "estava presa, sequestrada", mas um outro do discurso, ou do contradiscurso que falava dos alunos da escola que dirigia. Mas percebeu-se um apoio ao movimento, a partir da organização da população, a polícia não tinha como agir, pois, 
havia um documento elaborado por um advogado, legitimando o movimento, dando-lhe amparo legal.

"Ficamos lá, fizemos mutirão para limpar a escola e retrocederam aquele ano, como disse no próximo meu filho saiu de lá": a presença de um pronome pessoal "nós" na forma verbal "ficamos" demonstra o engajamento pessoal do sujeito no movimento de ocupação da escola em epígrafe; "fizemos mutirão para limpar a escola", reforça esse engajamento, essa resistência diante do processo de reorganização das escolas públicas do Estado de São Paulo, o que sinaliza um aspecto bastante importante e positivo, pois “(eles) retrocederam aquele ano", isto é, Eles/ o Estado, desistiram, até então, de implantar o processo de reorganização naquela escola, mas: "como disse no próximo meu filho saiu de lá" e então "Fecharam o período noturno", mais uma vez o sujeito se coloca como liderança no movimento, seja como mãe de aluno, mulher, cidadã. Enquanto o sujeito estava em vigília, resistindo, o Estado retrocedeu. "Quando Guilherme saiu de lá fecharam o período noturno".

\section{Considerações finas}

Pensamos que o momento para tal análise poderá ser significativo, já que a educação brasileira vive uma fase histórica de retrocessos, o que impele os estudantes ao exercício de um papel ativo na constituição de sua própria identidade, como visto nas ocupações. Além desse evento, os estudantes da UBES têm demonstrado sua atuação a favor da Universidade Pública e da manutenção do FUNDEB.

Compreendemos que as questões educacionais influenciam diretamente nas questões político-sociais e econômicas, e vice-versa. Dessa forma, é preciso considerar, na irrupção deste novo ideal de cidadania, a influência dos diversos discursos e contrapô-los à cultura globalizada neoliberal, objetivando a retomada dos direitos perdidos ao longo do processo histórico e a conquista de outros.

Pelo observado no estudo da discursividade, a falta de comunicação valida as relações de poder limitando o direito à educação, por isso a relevância das análises das falas de pessoas que estão submetidas às determinações governamentais, mas que não se sujeitam efetivamente a essa condição. Tal abordagem nos auxilia a compreender, em alguma medida, como se dá a luta de forças e o que está sendo colocado em jogo nos conflitos sociais.

Esse "olhar-leitor" ou "gesto de leitura" se inscreve no campo da AD que trabalha a investigação no limite do fenômeno linguístico com o social, objetivando trazer a "memória discursiva", 
mostrando um espaço tenso, movediço, de deslizes e retomadas, confrontos e regularização, polêmicas e contradiscursos num determinado momento histórico. Entre atualizações e subjetividades, interessa(m) ao analista o(s) efeito(s) produzido(s) por tal mecanismo (GAMA; FLORES, p. 9).

Para Orlandi (1999, p. 59-71), na memória se contemplam sentidos particulares, alguns até silenciados. A memória está repleta de imagens produzidas pelo que relata e age ideologicamente nos sujeitos sociais. Nem sempre, porém, o sentido é dado pelo sujeito de forma deliberada, pelo contrário, é delimitado e regido pelas instituições, conforme os interesses do momento. Assim, as diferentes formas de poder agenciam as identidades e as controlam, instituindo os sentidos.

Analisar tal discurso representa compreender que as instituições governamentais atuam por meio de gestão estratégica. Regulando a segurança pública e a saúde e, certamente, a educação para que estejam a benefício do poder. No tema estudado, percebe-se que essa forma de governo desconsidera fatores emocionais, como permanecer com seus professores e amigos na escola próxima a sua residência. À SEE/SP basta oferecer vaga. Nesse processo, relegam aspectos que envolvem a segurança de pessoas que vivem em territórios de exclusão e o direito de uma educação de qualidade. Fechar escolas e período noturno, concentrar alunos de uma região em um único espaço e obrigar os estudantes de regiões violentas a se locomoverem durante a noite, não são pontos importantes para a reflexão governamental. Lidam com pessoas como se fossem objetos totalmente manipuláveis. Mas como visto, houve uma reação. Nesse sentido, Foucault (1976) postula que toda forma de poder é indissociável das práticas de resistência e tal prática foi observada quando os estudantes ocuparam as escolas.

Para finalizar, reiteramos que a leitura dos enunciados apresentados aqui se constitui apenas em um modo de registrar a realidade desta mãe de estudante, a qual também participou do movimento denominado "ocupações". Nosso desafio foi o de construir interpretações na tentativa de não neutralizar o sentimento, a intenção e a inquietação da entrevistada diante da reorganização da escola que o filho estudava. Não se trata de um discurso universal, mas de uma realidade momentânea que representa a lógica/a imagem que ficou para esta participante que resistiu a tal forma de autoritarismo.

\footnotetext{
Notas

1 Tese defendida por Roseli Trevisan Marques de Souza em 06 de dezembro de 2019, sob orientação do Professor Dr. Afrânio Mendes Catani - Faculdade de Educação da Universidade de São Paulo - FE/USP. A investigação teve início nas Escolas Estaduais da capital paulista e depois foi ampliada para as escolas da Grande São Paulo para, finalmente chegar ao interior, que também teve escolas estaduais ocupadas. Na tese também são apresentadas as ocupações que aconteceram em 2016, em todo Brasil, nas quais os estudantes refutavam políticas federais de Educação. Trechos desse texto estão também no corpo da tese, tivemos a intenção neste artigo, de fazer uma análise que une campos de conhecimento, dando luz, nesse momento, ao discurso do sujeito entrevistado. Disponível em: https://www.teses.usp.br/teses/disponiveis/48/48134/tde-03032020-161506/pt-br.php. Acesso em: 23 nov. 2020.

2 Escola Estadual situada na capital de São Paulo.
} 
${ }^{3}$ Disponível em http://www.anped.org.br/sites/default/files/gt10-1937-int.pdf . Acesso em: 19 fev. 2019

${ }^{4}$ Recorte aqui entendido como "unidade discursiva; fragmento correlacionado de linguagem e situação (ORLANDI, 1987, p. 139)

5 [...] a imagem funciona como um "operador de memória social" na medida em que descreve "um percurso escrito discursivamente em outro lugar" (PÊCHEUX, 1999, p. 51), oferecendo aos sujeitos um "trajeto" de leitura que pode romper-se ao choque de um fato de discurso, dando margem a outras leituras.

${ }^{6}$ Escolas não identificadas da Zona Leste de São Paulo.

7 Todos os enunciados submetidos à análise foram recortados dos questionários, portanto, as possíveis ocorrências de "desvio" de questões gramaticais e linguísticas foram mantidas.

\section{Referências}

CHARAUDEAU, P. Discursos das mídias. São Paulo: Contexto, 2007.

DIJK, Teun A. van. Discurso e poder/Hoffnagel, J. \& Falcone, K. (orgs.) São Paulo: Contexto, 2004.

DUCROT, O. verbete "énonciation" Supplément à L'Encyclopaedia Universalis. 1980.

FOUCAULT, M. Securité, territoire, population: cours au Collège de France (1977-1978). Paris: Hautes Études/Gallimard-Seuil. 1978.

FOUCAULT, M. Vigiar e punir: nascimento da prisão. Petrópolis/RJ: Vozes. 1976.

GAMA, A.S.; FLORES, M. R. C.S. Livro de ocorrência; das práticas discursivas ao vigiar e punir. Disponível em: http:/ /linguisticaelinguagem.cepad.net.br/EDICOES/08/Arquivos/06.pdf. Acesso em: 24 set. 2020.

GOHN, M. da G. Movimentos e lutas sociais na história do Brasil. São Paulo: Loyola, 2013.

GREGOLIN, Maria do Rosário V. A análise do Discurso: Os sentidos e suas movências. In: Análise do Discurso: Entornos e Sentidos. Araraquara-SP: Cultura Acadêmica, 2001.

HALL, S. A identidade cultural na pós-modernidade. Rio de Janeiro: DP\&A. 2000.

LE GOFF, J. História e Memória, Editora Unicamp: São Paulo, 1996.

MAINGUENEAU, D. Novas Tendências em Análise do Discurso. Campinas: Pontes. 1993.

ORLANDI, E. P. (org.) [et al]. Gestos de Leitura: da história do discurso. Petrópolis: Vozes (2010).

ORLANDI, E. P. Interpretação: autoria, leitura e efeitos do trabalho simbólico. Petrópolis: Vozes, 2007.

ORLANDI, E. P. Discurso e leitura. São Paulo: Cortez, 2008.

ORLANDI, E. P. A linguagem e seu funcionamento. Campinas: Pontes, 2001.

PÊCHEUX, Michel. Discurso: Acontecimento ou Estrutura. Campinas. Pontes.2006. 
PÊCHEUX, Michel. Papel da Memória. In: ACHARD, P. at all. Papel da Memória. Campinas. Pontes. 1999.

TFOUNI, L. V.; ASSOLINI, F. E. Gestos de interpretação e de autoria em produções linguísticas orais e escritas: desafios e possibilidades. Disponível em: https://anped.org.br/sites/default/files/gt10-1937int.pdf. Acesso em: 22 set. 2020. 